\title{
A Bioética Cotidiana como instrumento de reflexão sobre a atenção à saúde da população LGBT
}

Everyday Bioethics as an instrument for reflection on the health care of the LGBT population

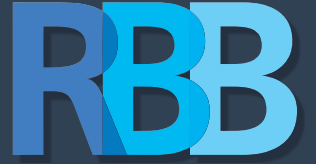

Revista Brasileira de Bioética

\section{Ana Luísa} Remor da Silva

- ० ०००००००

Programa de Pósgraduação em Saúde Coletiva. Universidade Federal de Santa Catarina, Florianópolis, SC, Brasil

๘ ana_remor@hotmail.com

\section{Fernando Hellmann}

- 0 0 0 0 00000

Departamento de Saúde Pública. Universidade Federal de Santa Catarina, Florianópolis, SC, Brasil

t fernando.hellmann@ufsc.br

Mirelle Finkler 00000000000

Departamento de Odontologia. Universidade Federal de Santa Catarina, Florianópolis, SC, Brasil

t

mirelle.finkler@ufsc.br

Marta Verdi - 0 ० 000000 Departamento de Saúde Pública. Universidade Federal de Santa Catarina, Florianópolis, SC, Brasil

$\Delta$

marverdi@hotmail.com
Resumo: A discriminação por orientação sexual e por identidade de gênero na determinação social da doença faz com que a problemática da atenção à saúde da população LGBT (Lésbicas, Gays, Bissexuais, Travestis e Transexuais) possa ser percebida também como uma questão de ordem ética. Reconhecendo a Bioética Cotidiana proposta por Giovanni Berlinguer enquanto potente referencial de análise de problemas éticos, propõe-se uma aproximação entre a atenção à saúde da população LGBT enquanto objeto de análise e o referido referencial teórico. Neste sentido, abordam-se inicialmente alguns conceitos que permitem evidenciar a moralidade implicada nas fobias de gênero, notadamente heteronormatividade, homofobia e cisnormatividade, para posteriormente traçar as aproximações possíveis entre a Bioética Cotidiana e a problemática da atenção à saúde da população LGBT. Considerou-se que a Bioética Cotidiana constitui um aparato reflexivo de profunda análise crítica à maneira como as questões de saúde e de vida como um todo são tratadas, podendo-se então incluir em sua pauta as situações atreladas às questões de gênero, discriminação e exclusão social.

Palavras-chave: bioética, atenção à saúde, minorias sexuais, preconceito.

Abstract: The discrimination based on sexual orientation and gender identity in the social determination of the disease makes the issue of health care for the LGBT population (Lesbian, Gay, Bisexual, Transvestite and Transsexual) a question of ethics. Recognizing the Everyday Bioethics proposed by Giovanni Berlinguer as a powerful reference for the analysis of ethical problems, it is proposed an approximation between the health care of the LGBT population as object of analysis and the referred theoretical reference. For this reason, some concepts that allow us to highlight the morality implied in gender phobias, notably heteronormativity, homophobia and cisnormativity, are presented, in order to later draw the possible approximations between Everyday Bioethics and the health care problem of the LGBT population. It was considered that Everyday Bioethics constitutes a reflective apparatus of deep critical analysis to the way in which the health and life issues as a whole are treated, being able to include in its agenda the situations linked to the issues of gender, discrimination and social exclusion.

Keywords: bioethics, health care, sexual minorities, prejudice. Introdução 
peso da discriminação por orientação sexual e por identidade de gênero na determinação social da saúde e, portanto, na geração de iniquidades em saúde, faz com que a problemática da atenção à saúde por parte da população LGBT (Lésbicas, Gays, Bissexuais, Travestis e Transexuais) deva ser percebida também, e principalmente, como uma questão de ordem ética. Mesmo porque toda discriminação, seja ela positiva ou negativa, decorre de julgamentos morais.

A dificuldade de desconstruir a discriminação negativa e promover o reconhecimento da identidade de gênero por parte dos trabalhadores da saúde tem sido um dos pontos centrais de limitação da atenção à saúde da população LGBT, diretamente vinculada à disputa das concepções de gênero no pensamento em saúde e no contexto mais ampliado da sociedade (Rogers, Tesser Jr, Moretti-Pires, 2016). A família, as instituições do Estado, de educação e de formação profissional, ainda são espaços de reprodução das normas da heteronormatividade, com manifestações importantes de violência simbólica contra pessoas não heterossexuais (Moscheta, Moretti-Pires, 2016).

As transformações e o novo ritmo no campo técnico-científico colaboraram para que as questões éticas deixassem de ser consideradas abstratas e teóricas para serem incorporadas nas discussões da saúde (Garrafa, 2012). Essa discussão (bio) ética fomentou diferentes referenciais de análise agrupados sob a denominação Bioética Social, por conta de situarem a Bioética numa análise estrutural da sociedade como produtora de vida e de condições de saúde (Hellmann, Verdi, 2012).

Diferentes correntes teóricas da Bioética Social permitiriam analisar os inúmeros e recorrentes problemas relacionados à atenção à saúde da população LGBT. Assim como a Bioética da Proteção, a Bioética da Intervenção e a Bioética Crítica de Inspiração Feminista, a Bioética Cotidiana é uma destas correntes, considerada um marco precursor das demais bioéticas deflagradas no Brasil e em outros países latino-americanos a partir da década de 1990 (Hellmann, Verdi, 2012, Lima, 2012).

Trata-se de um referencial construído a partir da atuação e das reflexões do médico-sanitarista-bioeticista italiano Giovanni Berlinguer (1924 - 2015), personalidade que contribuiu significativamente na reforma da saúde pública italiana, precursora e inspiradora à reforma sanitária brasileira com seu incentivo e participação (Lima, 2012).

Para a Bioética Cotidiana, "viver de modo digno significa viver e conviver em saúde" (Lima, 2012, p. 18), razão pela qual aborda temas relacionados à saúde coletiva e sua ocorrência na vida cotidiana, como as divergências e congruências entre a prática e as políticas públicas referentes à saúde e à sociedade, ultrapassando assim os grandes temas centrais da bioética denominada por Berlinguer de "fronteira", tais como a eutanásia, a clonagem, a reprodução humana assistida, entre outros. Ocupa-se de analisar as novas formas de nascer, viver e morrer das pessoas e comunidades, em um mundo tecnicamente avançado e globalizado, porém 
pleno de contradições, com uma parcela significativa da população sem acesso aos benefícios decorrentes dos avanços científicos e tecnológicos, o que leva à persistência de problemas antigos como a fome, a exclusão social, a pobreza, o racismo e o aborto, reduzidos pelo sistema capitalista como problemas de menor valor perante as questões emergentes.

Reconhecendo-se na Bioética Cotidiana um potente referencial de análise para as questões que envolvem a saúde da população LGBT, propõe-se aqui uma aproximação entre objeto e referencial teórico, a fim de contribuir com reflexões que ajudem a pensar caminhos para uma saúde pública mais equânime, promotora de uma sociedade mais inclusiva e justa. Neste sentido, abordam-se inicialmente alguns conceitos que permitem evidenciar a moralidade implicada nas fobias de gênero, notadamente heteronormatividade, homofobia e cisnormatividade.

\section{Fobias de Gêneros: conceitos, preconceitos e discriminação}

No decorrer da história, as práticas sexuais homoafetivas foram abordadas de diversas maneiras: socialmente aceitas como na Grécia antiga, ou recriminadas, desvalorizadas e até mesmo sujeitas à pena de morte, como ainda acontece em alguns países como Sudão, Arábia Saudita, Irã e lêmen, para citar alguns. A associação do sexo como pecado, partindo de uma moral religiosa, além de questões jurídicas relacionadas ao poder e ao controle são alguns dos fatores que influenciam na maneira que sexualidade é determinada socialmente, reprovando a homossexualidade como uma forma de se relacionar (Martins, Leite, Porto, Netto, 2014).

Dentre os conceitos que permitem pensar as relações em uma sociedade que valida um discurso segregador e discriminatório, tem-se a heteronormatividade, a homofobia e a cisnormatividade. A primeira está relacionada, segundo Berlant e Warner (2002), com a concepção da heterossexualidade imposta como um padrão normal de se relacionar. Desta forma:

a heteronormatividade é mais do que uma ideologia, preconceito ou fobia contra os gays e as lésbicas; produz-se em quase cada aspecto das formas e dos procedimentos da vida social: nacionalidade, Estado e lei; comércio; medicina e educação; produz-se também nas convenções e afetos da narratividade, o romance e outros espaços protegidos da cultura (Berlant, Warner, 2002, p. 238).

Berlant e Warner (2002) refletem ainda sobre a dificuldade de identificar a presença da heteronormatividade nos ambientes citados, visto que a heterossexualidade se encontra arraigada e propagada na cultura, e até mesmo na construção da personalidade. 
Assim como a heteronormatividade, é importante pontuar outro conceito relevante ao debate, o da homofobia, que parte de uma fundamentação moral na qual a homoafetividade é considerada de menor valor, inferior, ou fora do normal, e que por meio da ridicularização e de discursos de ódio, pode chegar a diversos extremos de violência - física, psicológica, entre outras (Borrillo, 2001). A homofobia

se manifesta, entre outras coisas, pela angústia de ver desaparecer a fronteira e a hierarquia da ordem heterossexual. Exprime-se por meio das injúrias e dos insultos cotidianos, mas aparece também nos discursos de professores e especialistas, ou permeando debates públicos [...] Invisível, cotidiana e disseminada, a homofobia participa do senso comum, embora leve, igualmente, a uma alienação dos heterossexuais. É por essas razões que se considera indispensável questioná-la tanto no que se refere às atitudes e aos comportamentos quanto no que diz respeito às suas construções ideológicas (Borrillo, 2001, p. 18-19).

Desta forma impõe-se uma "hierarquia" na sexualidade, em que a heterossexualidade é vista como superior, e por meio da homofobia mantém-se este status social (Borrillo, 2001). A homofobia pode ser ainda relacionada com o medo ou ódio das lésbicas, gays e bissexuais, também, em alguns casos, das travestis e pessoas transexuais, baseada na ideia de que as pessoas trans também não seriam heterossexuais. A transfobia seria especificamente o "preconceito e/ou discriminação em função da identidade de gênero de pessoas transexuais ou travestis" (Jesus, 2012, p. 29).

Por sua vez, o conceito de cisnormatividade refere-se à determinação de que a identidade de gênero normal seria a cisgênero. Para Jesus (2012), uma pessoa cisgênero seria aquela que se identifica com o gênero determinado em seu nascimento, já no caso as pessoas trans seriam aquelas que não se identificam com o gênero atribuído ao nascimento. Cabe também diferenciar gênero e orientação sexual, já que no senso comum há confusão entre estes conceitos, acabando por entendê-los erroneamente como sinônimos. Desta forma, conforme assinala a psicóloga Jaqueline Gomes de Jesus (2012):

Gênero é diferente de Orientação Sexual, podem se comunicar, mas um aspecto não necessariamente depende ou decorre do outro. Pessoas transgênero são como as cisgênero, podem ter qualquer orientação sexual: nem todo homem e mulher é "naturalmente" cisgênero e/ou heterossexual (Jesus, 2012, p. 13).

Compreendidos tais conceitos, é possível observar que há estudos que revelam que as introjeções socioculturais calcadas na homofobia e na hétero- 
cis-normatividade permeiam os atendimentos em saúde, o que acaba por resultar em atendimentos insuficientes e de má qualidade, que contribuem para o afastamento da população LGBT ao acesso à saúde (Mello, Perilo, Braz, 2011; Santos, Santos, Souza, Boery et al., 2015). Tal situação é geradora de sofrimento e pode interferir inclusive no processo de adoecimento dessa população. Desta forma, a discriminação pela orientação sexual pode ser entendida também como um importante conflito ético entre profissionais e pacientes (Santos, Santos, Souza, Boery et al., 2015) e até mesmo entre os usuários e os sistemas de saúde.

Apesar das dificuldades e problemas de saúde serem compartilhados por toda a população, é inevitável apontar a presença de disparidades no atendimento à saúde quando se trata da população LGBT, os quais demandam relações clínicas livres de julgamentos moralistas. Desta forma, o profissional de saúde deve ser proativo e ter sensibilidade para conversar com o usuário sobre sua história de vida, orientação sexual e identidade de gênero, mantendo um ambiente confortável e seguro. Apenas com essa aproximação entre profissional e paciente, será possível um atendimento de qualidade que contemple as suas necessidades específicas (Makadon, 2011). Do mesmo modo, as políticas públicas contribuem para as transformações nas relações entre os profissionais que prestam serviços de saúde e os usuários.

No exemplo brasileiro, como comprometimento ético de todos os atuantes do Sistema Único de Saúde (gestores, trabalhadores da saúde, conselheiros, dentre outros), deu-se início à instituição de ações de combate à discriminação de LGBT nos locais de serviço e atendimento público de saúde. Desta forma, para a humanização do cuidado à saúde da população LGBT em termos também de promoção, proteção e prevenção da saúde, a Política Nacional de Saúde Integral de Lésbicas, Gays, Bissexuais, Travestis e Transexuais - PNSI LGBT entende como fundamental a importância do atendimento livre de preconceitos e discriminação, com respeito e inclusão social. Tais medidas são essenciais para se consolidar um Estado laico, com promoção da democracia social e ainda, ampliação da compreensão sanitária em busca da defesa dos direitos sexuais como elementos essenciais da saúde e do direito a ela (Brasil, 2013).

A despeito de alguns avanços, há ainda uma grande distância entre o que a PNSI LGBT propõe e a prática cotidiana. Por exemplo, e conforme apontam Rogers, Tesser Jr e Moretti-Pires (2016), o uso do nome social é garantido pela PNSI LGBT em todas as esferas do SUS, porém, um dos problemas mais recorrentes vivenciados pelas (os) participantes trans em sua pesquisa foi a questão do não reconhecimento do nome social nos serviços de saúde, caracterizando uma violência institucional que fere a identidade das pessoas e dificulta seu real acesso. Outros fatores relevantes foram a falta de conhecimento dos profissionais a respeito das peculiaridades no atendimento a pessoas trans, a pouca empatia e sensibilidade durante este processo. Desta forma, há pouca confiança 
o que faz com que muitos deixem de procurar por assistência à saúde, contribuindo ainda mais para a vulneração desta população.

Toda política pública emana valores. Às vezes, tais valores contrastam com os prevalentes na sociedade. Berlinguer (2004) refere que quando certas escoIhas individuais ou coletivas que influenciam na dinâmica da população começam a se destacar, passam a estar sujeitas a julgamentos morais dos mais variados, o que gera conflitos que são objeto de análise para a bioética.

\section{Bioética Cotidiana e a problemática da população LGBT: aproximações possíveis}

Berlinguer (1993) aponta que a segunda metade do século XX foi marcada por um grande salto científico no âmbito das ciências biológicas, física, química, dentre outras, com um avanço tecnológico rápido, intenso e profundo. Sua crítica refere que este ritmo de ações grandiosas que atraem os especialistas e orientam as informações acabam por contribuir para uma tendência predominante em se refletir e discutir "situações-limite ou de fronteira" vivenciadas por minorias, o que acarreta na negligência de problemas morais e científicos importantes presentes na vida cotidiana de milhares e até milhões de pessoas. Desta forma por muitas vezes a bioética acaba por privilegiar debates sobre situações extremas (ou situações limites), como eutanásia, transplante de órgãos, fertilização in vitro, esquecendo-se de acrescentar, nas pautas de discussões, questões básicas da saúde, para qual frequentemente "é negado o título de nobreza como objeto da ética e, na melhor das hipóteses, Ihe é atribuído apenas o valor (que para alguns é considerado filosoficamente irrelevante e intelectualmente plebeu) de 'questão social'" (Berlinguer, 1996, p. 16).

Berlinguer (1996) aponta a necessidade de investir no debate bioético não apenas nas situações limites, mas também aquelas persistentes na vida cotidiana de todos. No campo das questões de gênero, por exemplo, se por um lado, a evolução das técnicas e tecnologias permitiu realizar cirurgias de redesignação sexual e com isso suscitar problemas a serem discutidos no âmbito da bioética - a exemplo da medicalização dos "transtornos de identidade de gênero", mais recentemente denominados de "Disforia de Gênero" - por outro, o preconceito e as diferentes tipologias da violência - de física à psicológica - vivida e sofrida pela população LGBT são problemas cotidianos e persistentes.

A Bioética Cotidiana, como ensina Berlinguer (2004; Berlinguer, 1996), está para além das discussões a respeito das questões de fronteira como a vida e a morte, as quais são importantes de serem debatidas, mas não são as únicas pautas. Deve-se quebrar o silêncio e a incerteza que pairam sobre a macroética em relação àqueles temas persistentes historicamente e que influenciam nas questões de saúde cotidiana (Berlinguer, 1996). 
Atualmente, com o progresso das ciências médicas e da área da saúde em geral, nunca se teve tantas possibilidades de intervenção de forma segura, tantas doenças curáveis e mortes preveníveis. A saúde, paradoxalmente, ao mesmo tempo em que se encontra próxima a todos pela presença de diversos recursos, encontra-se distante e pouco acessível para uma grande parcela da população mundial, pela falta de interesse e intenção de usar estes recursos (conhecimentos, soluções) para o bem de todos. Desta forma, globalizam-se os riscos e as consequências negativas, e restringem-se as soluções e o desenvolvimento. "O dano atinge as pessoas, classes, etnias e populações seletivamente, ainda que não exclusivamente, na proporção inversa ao patrimônio à instrução e ao poder, por isso reduzindo ou reforçando as condições de iniquidade" (Berlinguer, 2004, p. 248).

Ainda que o autor não tenha tratado diretamente sobre questões de saúde da população LGBT, pode-se perceber um tom não sexista em seu discurso, baseado na igualdade de gêneros e no respeito do pluralismo das ideias e das diferentes formas de existir. Berlinguer (2004) faz uma análise entre a palavra homossexualidade e os valores atrelados a ela. A palavra homossexualidade, por si só é moralmente neutra, porém apresenta uma conotação histórica associada à culpa ou ao crime. Outra questão importante a respeito da palavra homossexualidade foi a sua característica nosográfica designada pela nomenclatura sanitária internacional, até que os movimentos LGBT conseguiram, com muita luta, a sua despatologização.

Em um estudo sobre representações sociais da homossexualidade com estudantes universitários do Rio de Janeiro, realizado por Scardua e Souza Filho (2006), como parte dos resultados, obtiveram a concepção de caráter intencional da homossexualidade, por maior parte dos estudantes heterossexuais. Para os autores, uma das possíveis críticas a serem feitas em relação a esse fato seria que, ao utilizar da noção de intencionalidade da homossexualidade, os estudantes heterossexuais poderiam assim justificar uma responsabilidade e até mesmo a culpabilização das pessoas homossexuais pela sua orientação sexual. comportamentos que também naturalizam ações discriminatórias e preconceituosas.

Nesta mesma lógica de compreensão dos (des) valores associados à visão moralista de uma parcela da sociedade a respeito das pessoas LGBT é interessante retomar a ideia do desvio social, criticada por Berlinguer (1996). Esta lógica confirma o mito de que cada um faz ou recebe por merecer, o que acaba por naturalizar a ideia de que as pessoas são "responsáveis" pelas próprias desgraças. Assim, retomam-se visões antigas de temáticas morais que acabam por relacionar doença e culpa, justiça e saúde, dentre outras. Tendo esta perspectiva como base, o exercício ético se torna limitado (Berlinguer, 1996). 
No entanto, a medicina ocidental demonstrou que a saúde, boa ou má, não é um evento imutável, mas sim passível de modificação, e ainda, substituiu as ideias sacras de destino e culpa sempre associadas às doenças, por ideia laica, fundamentada na experiência: a ideia de que é possível enfrentar e vencer muitas doenças (Berlinguer, 1996). Desta forma, saúde passa a ser considerada um valor desejável e alcançável por meio do progresso humano, porém, nem sempre conseguida, visto que pouco frequentemente a saúde é percebida como uma necessidade e, acima de tudo um direito (Berlinguer, 1996).

As pautas de lutas dos movimentos LGBT são justamente direitos básicos de vida com os quais esta população encontra-se ainda privada de usufruir, seja pela falta de um aparato legal que respalde a garantia desses direitos, seja por barreiras impostas socialmente por uma parcela da população atrelada a uma visão conservadora, homofóbica, hétero cisnormativa (Silva, Finkler, 2016). Por direitos básicos compreende-se um mínimo de garantias para se viver com dignidade e poder assim desenvolver o seu potencial como pessoa (Brasil, 1988). Ao encontro deste contexto, Berlinguer (2004, p. 258) destaca o seu entendimento por equidade em saúde, que seria: "criar, ou favorecer, para cada indivíduo, a possibilidade de perseguir e de atingir o nível potencial de saúde que lhe é próprio" (grifo do autor).

A universalidade do acesso à assistência e a equidade como princípios fundamentais para o direito à saúde requerem propostas de estratégias de acolhimento e atenções voltadas às especificidades e particularidades daqueles que buscam os serviços de saúde. Isto implica incluir no debate bioético os determinantes e condicionantes da saúde, tais como também são as questões de sexualidade e identidade de gênero. Já está claro que dificuldades de acesso à saúde pela população LGBT estão atreladas também ao preconceito, à discriminação, à visão binária de gênero compartilhada por muitos profissionais de saúde, e também por grande parte da população (Mello, Perilo, Braz, 2011). Nota-se que as barreiras de acesso à saúde serão minimizadas com o rompimento dos processos de discriminação institucionalizados (Lionço, 2008). Desta forma, ainda há muito a ser conquistado em relação à universalidade de acesso e à integralidade da atenção à saúde, principalmente em relação à população LGBT no panorama internacional e no Brasil em particular.

\section{Considerações Finais}

Nesta breve aproximação entre a problemática da atenção à saúde da população LGBT e a Bioética Cotidiana, considerou-se que a última constitui um aparato reflexivo de profunda análise crítica à maneira como as questões de saúde e de vida como um todo são tratadas, podendo-se então incluir em sua pauta as situações atreladas às questões de gênero, discriminação e exclusão social. 
A saúde como um direito de todos é um dos principais focos de discussões abordadas por Berlinguer $(2004,1996)$. Percebe-se que a forma em que os sistemas de saúde se constituem acaba por ser insuficientes quando se pensa em saúde de populações que fogem do padrão cisgênero e heterossexual. Lançar mão de estratégias de inclusão com forte caráter equitativo é condição fundamental para o avanço em direção à superação das iniquidades presentes na triste realidade da vida cotidiana da população LGBT.

À bioética cabe trazer para o centro dos debates as situações da vida cotidiana negligenciadas sistematicamente pelo Estado, pela ciência, pela sociedade. Aos bioeticistas cabe a reflexão contundente acerca da discriminação, do desvalor sofrido por esse grupo social, bem como a ação crítica e comprometida com a inclusão dessas pessoas no sistema de saúde e a transformação das práticas tendo por base a humanização do cuidado.

\section{Referências}

1. Berlant L; Warner M. Sexo em Público. In: Jiménez RMM (ORG). Sexualidades Transgressoras. Barcelona: Içaria, 2002. p.229-257.

2. Berlinguer G. Bioética cotidiana. Brasília: UnB, 2004.

3. Berlinguer G. Ética da Saúde. São Paulo: HUCITEC. 1996.

4. Berlinguer G. Questões de vida: ética, ciência, saúde. Salvador/São Paulo/Londrina: APCE/HUCITEC/CEBES. 1993.

5. Borrillo D. Homofobia. Barcelona: Bellaterra, 2001.

6. Constituição da República Federativa do Brasil. Brasília: Senado Federal. 1988.

7. Ministério da Saúde. Secretaria de Gestão Estratégica e Participativa. Departamento de Apoio à Gestão Participativa. Política Nacional de Saúde Integral de Lésbicas, Gays, Bissexuais, Travestis e Transexuais / Ministério da Saúde, Secretaria de Gestão Estratégica e Participativa, Departamento de poio à Gestão Participativa. Brasília: Ministério da Saúde, 2013.

8. Garrafa V. Proteção e acesso à saúde como um bem social. In: Hellmann F et al. Bioética e Saúde Coletiva: perspectivas e desafios contemporâneos. Florianópolis: DIOESC, 2012. p.36-51

9. Hellmann F; Verdi M. Bioética social: reflexões sobre referenciais para a saúde coletiva. In: In: Hellmann F et al. Bioética e Saúde Coletiva: perspectivas e desafios contemporâneos. Florianópolis: DIOESC, 2012. p.52-64.

10. Jesus JG. Orientações sobre identidade de gênero: conceitos e termos. Brasilia, 2.ed., 2012.

11. Lima RCGS. Giovanni Berlinguer: uma história de luta pela consolidação do direito à saúde. In: Hellmann F et al. Bioética e Saúde Coletiva: perspectivas e desafios contemporâneos. Florianópolis: DIOESC, 2012. p.18-35. 
12. Lionço T. Que direito à saúde para a população GLBT? Considerando direitos humanos, sexuais e reprodutivos em busca da integralidade e da equidade. Saúde e Sociedade, 2008, 17(2):11-21.

13. Makadon HJ. Ending LGBT invisibility in health care: The first step in ensuring equitable care. Cleveland Clinic Journal of Medicine, 2011, 78(4):220-224.

14. Martins EST, Leite RL, Porto TS, Netto OFL. Psicanálise e homossexualidade: da apropriação à desapropriação médico-moral. Ide, 2014; 36(57):63-177.

15. Mello L, Perilo M, Braz CA; Pedrosa C. Políticas de saúde para lésbicas, gays, bissexuais, travestis e transexuais no Brasil: em busca de universalidade, integralidade e equidade. Sexualidad Salud y Sociedad, 2011, 9(1): 7-28.

16. Moscheta MS; Moretti-Pires RO. Gênero, Sociedade e Transformações. Saúde \& Transformação Social, 2016; 7(3):i-ii.

17. Rogers J; Tesser Jr ZC; Moretti-Pires RO. Pessoas Trans na Atenção primária: análise preliminar da implantação no município de Florianópolis, 2015. Saúde \& Transformação Social, 2016; 7(3):49-58.

18. Santos A, Santos RMM, Souza ML, Boery RNSO, Sena ELS, Yarid SD. Implicações bioéticas no atendimento de saúde ao público LGBTT. Revista Bioética, 2015, 23(2):400-408.

19. Scardua A; Souza Filho EA. O debate sobre a homossexualidade mediado por representações sociais: perspectivas homossexuais e heterossexuais. Psicologia: Reflexão e Crítica, 2006, 19(3):482-490.

20. Silva ALR; Finkler M. O movimento LGBT e a bioética crítica de inspiração feminista: convergências e potencialidades. Saúde \& Transformação Social, 2016, 7(3):1-10.

Recebido em: 27/08/2017. Aprovado em: 15/09/2017. 